\title{
Ultrasonic Synthesis of Polysodium-4-styrene Sulfonate coated Functionalized MWCNTs for Electrochemical Detection of Anti-Oxidant Drug in Red Wine
}

\author{
Ragu Sasikumar ${ }^{1}$, Tse-Wei Chen ${ }^{1,2}$, Shen-Ming Chen ${ }^{1,2, *}$, Yu Chi Chen ${ }^{1}$, Syang-Peng Rwei ${ }^{2,3}$ \\ ${ }^{1}$ Department of Chemical Engineering and Biotechnology, National Taipei University of Technology, \\ No. 1, Section 3, Chung-Hsiao East Road, Taipei 106, Taiwan, ROC. \\ ${ }^{2}$ Research and Development Center for Smart Textile Technology, National Taipei University of \\ Technology, Taipei 106, Taiwan, ROC \\ ${ }^{3}$ Institute of Organic and Polymeric Materials, National Taipei University of Technology, Taipei 106, \\ Taiwan, ROC \\ *E-mail: smchen78@ms15.hinet.net.
}

doi: $10.20964 / 2018.10 .57$

Received: 11 June 2018/ Accepted: 12 August 2018 / Published: 1 September 2018

\begin{abstract}
A greatly selective, and sensitive 3,4-Dihydroxy-trans-cinnamate sensor based on a poly (sodium 4styrenesulfonate) (PSSS) coated with functionalized multiwalled carbon nanotubes (PSSS@fMWCNTs) composite modified electrode was improved. The fabricated PSSS@f-MWCNTs/GCE displayed an excellent voltammetric response for caffeic acid to compared control electrodes. Under optimum conditions, the modified electrode showed a wide linear range at caffeic acid concentrations

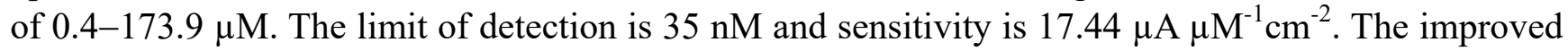
sensor method was showed good anti-interference, reproducibility, good repeatability, and excellent storage stability.
\end{abstract}

Keywords: Poly (sodium 4-styrenesulfonate), 3,4-Dihydroxy-trans-cinnamate, TGA, Co-polymer, Ionic polymer.

\section{$\underline{\text { FULL TEXT }}$}

(C) 2018 The Authors. Published by ESG (www.electrochemsci.org). This article is an open access article distributed under the terms and conditions of the Creative Commons Attribution license (http://creativecommons.org/licenses/by/4.0/). 